\title{
Discussion on the origin of surface failures in the Valley of Aguascalientes, México
}

\author{
M. Hernández-Marín ${ }^{1}$, N. González-Cervantes ${ }^{1}$, J. Pacheco-Martínez ${ }^{2}$, and D. H. Frías-Guzmán ${ }^{3}$ \\ ${ }^{1}$ Departamento de Geotecnia e Hidráulica, Universidad Autónoma de Aguascalientes, Aguascalientes, México \\ ${ }^{2}$ Departamento de Construcción y Estructuras, Universidad Autónoma de Aguascalientes, \\ Aguascalientes, México \\ ${ }^{3}$ Doctorado en Ciencias de los Ámbitos Antrópicos, Universidad Autónoma de Aguascalientes, \\ Aguascalientes, México \\ Correspondence to: M. Hernández-Marín (mhernandez@ correo.uaa.mx)
}

Published: 12 November 2015

\begin{abstract}
Surface failures have been observed in the valley of Aguascalientes since the early 1980's. Although, groundwater pumping began in the early 1950's but became intensive until the late 1970's, when many of the surface failures appeared. For this reason, surface deformation (surface failures and land subsidence) has been associated to groundwater withdrawal. Recent observations, however, suggest that some of these surface discontinuities are the result of natural geologic stresses rather than those associated groundwater decline, at least in its origin. Geologically, this valley is a tectonic graben flanked by two north-to-south trending normal faults, and seismicity of low intensity has been detected into the valley evidencing that the study area is seismically active. In this work, we present and discuss evidence showing tectonic discontinuities on the surface or at a shallow depth. Evidence presented in this investigation brings up uncertainty about the purely pumping-induced origin of fissuring in the valley, and allows addressing some key questions, for instance, are the surface failures caused by the combined stresses of pumping and tectonism? Is the current tectonism sufficient to cause some surface or deep failures?
\end{abstract}

\section{Introduction}

Mechanisms to origin surface discontinuities (faults or fissures) in urbanized valleys are variable. In the valley of Aguascalientes, three possible causes for the occurrence of ground failures (fissures and faults) were suggested: groundwater pumping, tectonic stresses and creep-type displacement (Aranda-Gómez, 1989). Most of the surface discontinuities were first observed by the early 1980's, when damages to several constructions were documented (Aranda-Gómez and Aranda-Gómez, 1985; UNAM-SOP, 1994; Lermo et al., 1996). Due to the close relation in time between of massive occurrences of surface discontinuities and the starting of the heavy groundwater pumping, it has been accepted that groundwater depletion is the main cause for the occurrence of these discontinuities. However, recent observations suggest ages of several decades, centuries or even thousands of years of formation. Here we present and discuss some of these observations. Figure 1 shows an outlook of the valley of Aguascalientes, main urban areas, and surface discontinuities.

\section{Observations on the Oriente Fault}

The named Oriente Fault (oriente means eastern in Spanish), flanks the Aguascalientes valley on the east, as observed in Fig. 1. In some branches, this fault is observed as a fissure and in others as a fault. In few locations is not shown at the surface (hidden by recent sediments?), but in others is observed as parallel alignments of two or three discontinuities. It is one of the most active in the valley, as evidence of that, the paved crossing roads over the trace failure trace are continuously repaired. It is also one of the most affected surface discontinuities by weathering because in some points, 


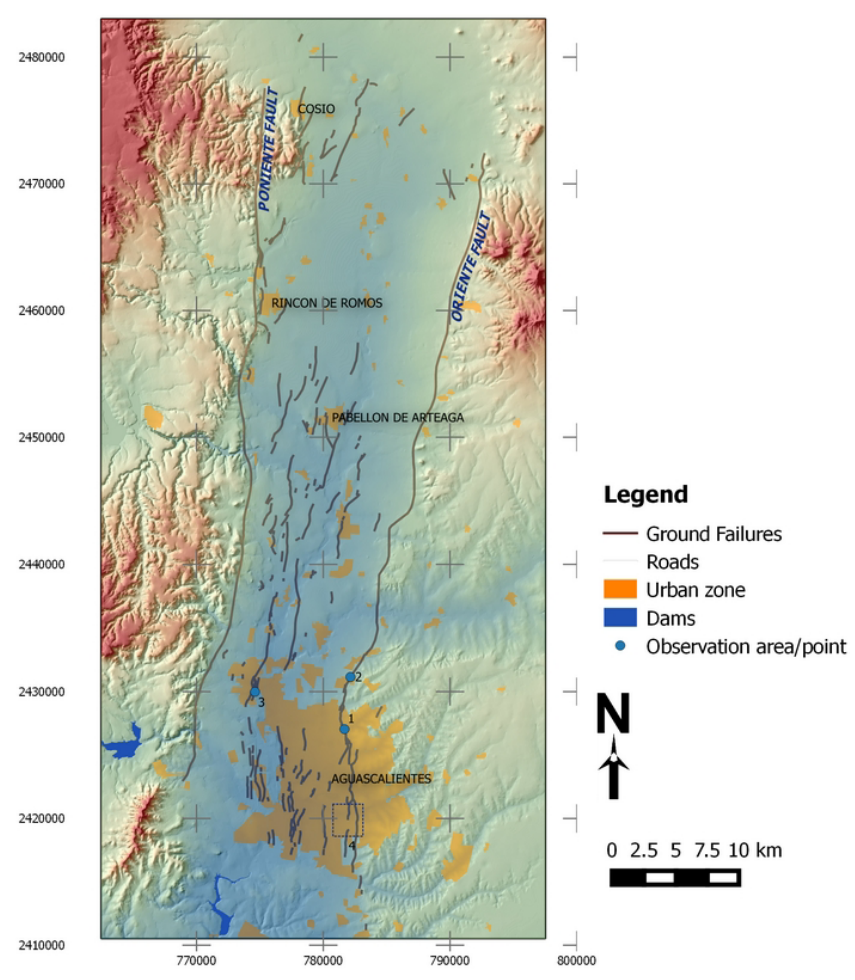

Figure 1. Main features of the Aguascalientes basin. Areas and points of observation in the map are referred according to figures: point 1 to Fig. 2, area 4 to Fig. 3, point 2 to Fig. 4, and point 3 to Fig. 5.

the opening is of more than $1 \mathrm{~m}$ and the observable depth can reach $2 \mathrm{~m}$. Photographs in Fig. 2a and b show the geometric characteristics of this fault (point 1 in Fig. 1). Another important point of discussion can be observed in the quarry of Fig. $2 \mathrm{c}$ and d. There, figures show an approximate quarry depth of $8 \mathrm{~m}$, and as observed, alluvial sediments on the left are not shown on the right, this mean that there is a fault offset higher than $8 \mathrm{~m}$. The fact that the fault plane cuts the entire upper sedimentary sequence indicates continuous activity of the fault in recent years. Also, the relative large fault offset may indicate that this activity started many years ago, prior groundwater pumping.

\section{Comparison of aerial photographs}

As presented in Pacheco-Martínez et al. (2013), the comparison of images containing a fault in two different years suggests that the origin of some surface discontinuities is natural, prior the pumping-induced subsidence process. In Fig. 3, the photograph of the left is from the early 1970's, before the occurrence of heavy pumping, however, the alignment of bushes clearly suggests an incipient discontinuity at the surface. It probably was well formed at depth by then. The discussion on this observation lies on the activity of this discontinuity at this particular point: since this fault flanks the

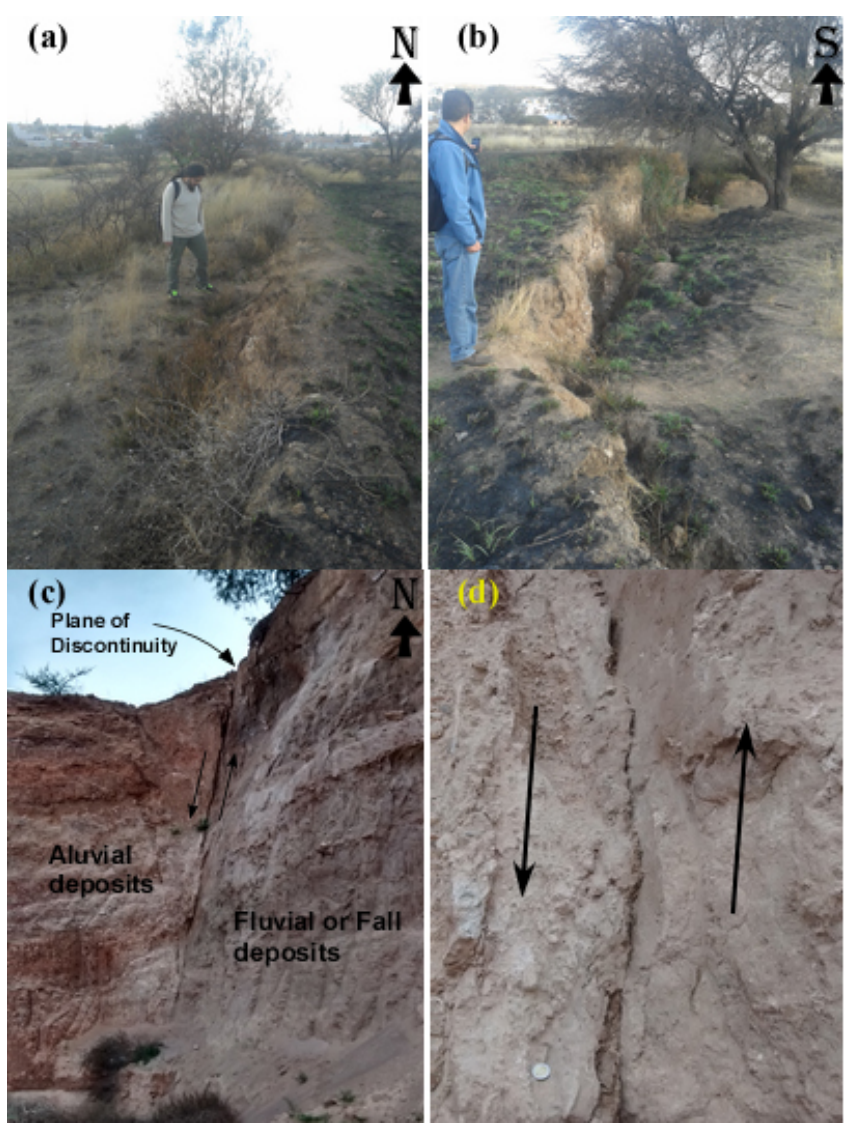

Figure 2. Fotographs depict some characterisitics of the Oriente fault inside the city of Aguascalientes. Difference between the base and the surface in the quarry in panels (c) and (d) is close to $8 \mathrm{~m}$.

valley and contributed to the origin of the valley the graben, then it is easy to think that this fault is tectonic in origin, However, the discussion here is the fact that tectonic activity could continue by the early 1970's, therefore this fault might be geologically defined as active.

\section{Formation of refilled cracks}

The observed refilled cracks with carbonates in the Oriente fault reinforce the idea of quaternary tectonic activity stressing on the valley, which generated faults and cracks currently reactivated due to induced stresses by groundwater decline. As discussed in Pacheco-Martínez et al. (2013), a representative $1 \mathrm{~cm}$-width crack in a region with climate similar to that in the valley of Aguascalientes, can last between 100 and 500 years per linear meter to be refilled with caliche, a time sufficiently long before the initiation of heavy pumping. As observed in the figure all cracks are closely parallel between them and their orientation quite similar to that of the main discontinuity at regional scale. Point 2 in Fig. 4 shows the location of observation for these refilled cracks. 

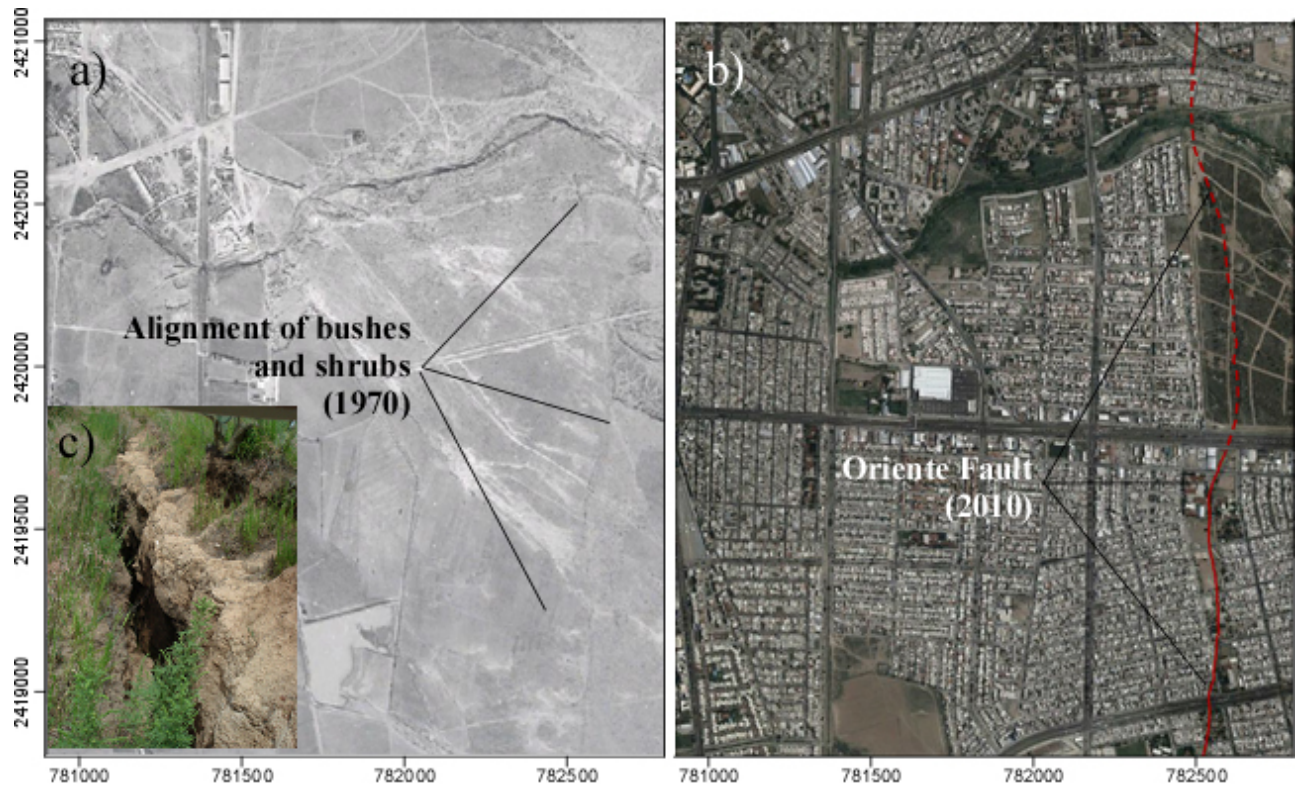

Figure 3. Comparison of two zones before and after intensive pumping (modified from Pacheco-Martínez et al., 2013). The particular location of this area is indicated in Fig. 1 with number 4.

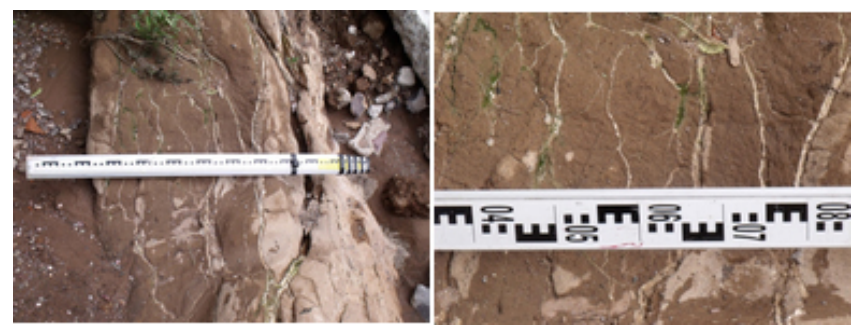

Figure 4. Filled cracks inside the zone of influence of the Oriente Fault. Refill consisted in groundwater caliche with a maximum thickness of $1 \mathrm{~cm}$.

\section{Fault offset on upper sedimentary layers}

In order to elucidate on the existence of buried cracks potentially becoming in surface discontinuities, it is a common practice in the Aguascalientes Valley to excavate trenches. This activity is usually performed to complement the geophysical studies and allows either confirming or dismissing buried ground discontinuities. When a buried soil crack is confirmed, they can observe their path, describe the mechanical damage of the adjacent geologic material, and define the potential influence zone on both sides of the discontinuity. Figure 5 shows a fault cutting the upper sediments into a trench. An offset of more than $1.5 \mathrm{~m}$ was observed. This fault however is not the Oriente fault. This observation indicates that intra-basin faults may be also older than the pumpinginduced subsidence process. This fault may represent an old fault reactivated by groundwater pumping.

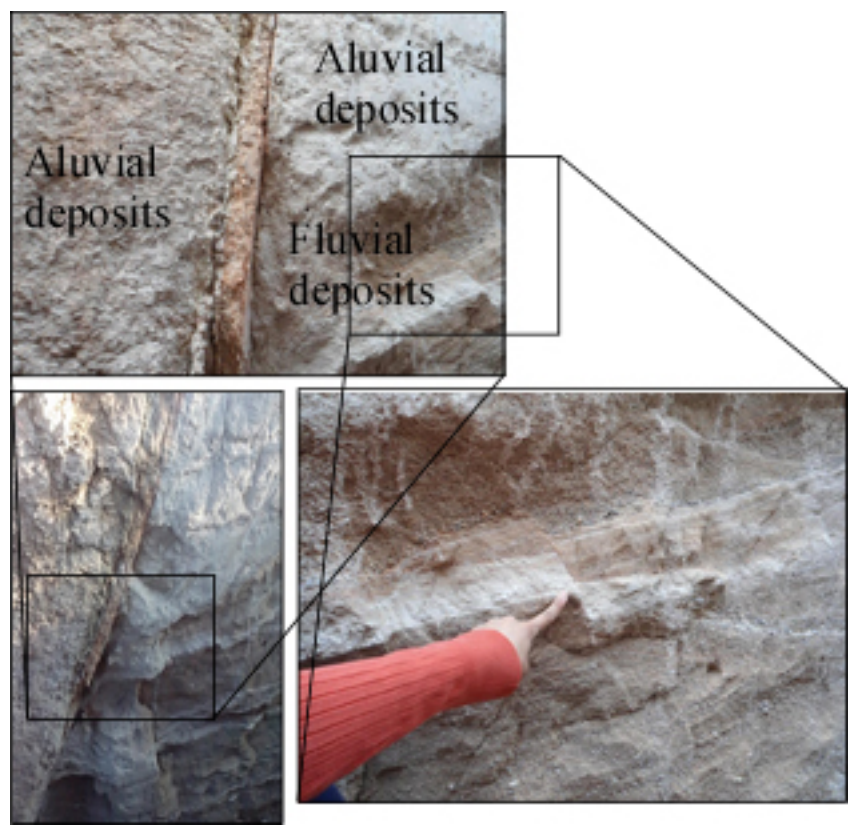

Figure 5. Trench excavated to physically observe a fault at depth. This is point 4 in Fig. 2. Observations indicate that hanging wall seems to be on the west of the fault, not to the east, which is toward the center of the valley.

\section{Future work}

Future work regarding surface deformation in the valley of Aguascalientes includes the geophysical and geohydrological characterization of more zones affected by surface dis- 
continuities, with particular emphasis in the oriente fault. Also, more observations on excavations with discontinuities are expected in order to understand more the origin of these structures in the valley. The new code of construction in the valley requires the physical observation of the upper $(<2 \mathrm{~m}$ depth) sediments in order to detect or dismiss potential discontinuities. These excavations will help to observe more details in this type of structures.

\section{Summary and conclusions}

Some observations regarding the origin of surface discontinuities in the valley of Aguascalientes are presented and discussed. Most of observations are on the Oriente fault, which flanks the semi-graben of Aguascalientes in its eastern portion. This fault presents recent activity and appears to be active in the last decades or even centuries. Intensive pumping started in the late 1970's; then, in few years many surface discontinuities were observed. However, observation presented in this work suggests that some of these discontinuities were originated long time before. There is doubt about how many of these discontinuities were originated long before intensive pumping, but there is certain that most of them appeared on the surface simultaneously to intensive pumping and continue developing at these days. The evidence presented in this work, suggests that some of the current active surface discontinuities were originated by stresses other than pumping (tectonic?).

Acknowledgements. Diego H. Frías-Guzmán is thankful to CONACYT for financial support.

\section{References}

Aranda-Gómez, J. J.: Geología preliminar del graben de Aguascalientes, Revista Mexicana de Ciencias Geológicas, 8, 22-32, 1989.

Aranda-Gómez, J. M. and Aranda-Gómezomez, J. J.: Análisis del agrietamiento en la ciudad de Aguascalientes, Informe anual preparado para el Departamento de Geotecnia del Centro Tecnológico, Autonomous University of Aguascalientes, Aguascalientes, México, unpublished results, 1985.

Lermo, J., Nieto-Obregon, J., and Zermeño-De-Leon, M. E.: Faults and fractures in the Aguascalientes Valley. Preliminary microzonification. Proceedings of the Eleventh World Conference on Earthquake Engineering. Acapulco, Mexico, Elsevier Science Ltd. Ed., Paper No. 1651, 8 pp., 1996.

Pacheco-Martínez, J., Hernandez-Marín, M., Burbey, T. J., González-Cervantes, N., Ortíz-Lozano, J. A., Zermeño-DeLeon, M. E., and Solís-Pinto, A.: Land subsidence and ground failure associated to groundwater exploitation in the Aguascalientes Valley, Mexico, Eng. Geol., 164, 172-186, doi:10.1016/j.enggeo.2013.06.015, 2013.

UNAM-SOP: Monitoreo sísmico y análisis estructural de las grietas en la ciudad de Aguascalientes, Informe técnico preparado por el Instituto de Ingeniería de la UNAM para la Secretaria de Obras Publicas del estado de Aguascalientes, Aguascalientes, México, Internal project No. 142/93, unpublished results, 1994. 